\title{
PERSPECTIVES
}

SCIENCE AND SOCIETY

\section{Current controversies in brain death determination}

\section{Ariane Lewis and David Greer}

Abstract | Although the concept of brain death is accepted by the majority of physicians, lawyers, ethicists and society at large, controversies about determination of death by neurological criteria persist, and often reach the public eye. In this article, we examine four prominent controversial brain death cases from 2013-2016. We review current controversies, including protocol variability, recognition of the American Academy of Neurology (AAN) criteria for brain death as an accepted medical standard, and management of objections to discontinuation of organ support after determination of brain death. Brain death remains conceptually and legally valid, and it is vital that these issues are solved. We argue that medical societies and governmental regulatory bodies must support the AAN criteria in order to decrease protocol variability, and must fully endorse the validity of these criteria as accepted medical standards.

The concept of death by neurological criteria is supported by a consensus of critical care professionals and clinicians involved in death determination around the world ${ }^{1-5}$, yet some people perceive it to be tantamount to a legal fiction and believe that only cardiopulmonary death is true death ${ }^{4}$. In the past few years, a number of highly publicized cases have arisen following evaluation of patients with catastrophic brain injuries for determination of brain death ${ }^{6-10}$. These cases, which were aggrandized by the media, questioned some of the core concepts of brain death, often without adequate rebuttal from the medical community. In this article, we use a selection of these cases (TABLE 1) to examine contemporary controversies in brain death determination.

\section{Criteria for brain death}

The first criteria for brain death determination were created by the Harvard ad hoc committee in 1968 (REF. 11). Subsequently, multiple organizations introduced guidelines on brain death determination, which employed similar but not identical - protocols $^{12}$.

The American Academy of Neurology (AAN) published criteria for determination of brain death in adults in 1995 (REF. 13), and updated them in 2010 (REF. 14). These guidelines require identification of the brain injury aetiology; confirmation of normal haemodynamics and absence of complicating factors such as pharmaceuticals or laboratory abnormalities that could affect the clinical examination; and demonstration that a patient is comatose, lacks brainstem reflexes, and cannot breathe spontaneously. If a portion of the neurological examination is medically contraindicated, an ancillary test such as an EEG or angiogram can be used to confirm lack of brain activity or blood flow to the brain ${ }^{14}$.

Currently, the AAN guidelines are considered to be the bedrock of brain death determination throughout the USA and in many countries around the world ${ }^{15}$, but institutional protocols deviate from the AAN guidelines both nationally and internationally in terms of prerequisites, examiner qualifications, ancillary testing, and apnoea testing ${ }^{16,17}$. In addition, some countries adhere to the UK philosophy that determination of death by neurological criteria requires brainstem death rather than whole-brain death ${ }^{4}$.
Guidelines for determination of brain death in paediatric patients were published by the American Academy of Pediatrics (AAP) in 1987, and were updated in 2011 by the AAP in conjunction with the Child Neurology Society and the Society of Critical Care Medicine ${ }^{18,19}$. These guidelines are similar, but not identical, to the adult guidelines ${ }^{14,19,20}$.

\section{Objections to brain death}

In 2015, the heterogeneity in brain death protocols brought the validity of the AAN criteria into question. Aden Hailu, a 20-year-old woman, was declared brain dead in a Nevada hospital after an intraoperative anoxic event. Her father did not accept that she was dead, as her heart was still beating, so he filed a lawsuit to prevent the hospital from discontinuing organ support. A district court found that Aden met the AAN criteria for brain death and, thus, she was legally dead and organ support should be discontinued. Aden's father appealed the decision.

The Supreme Court of Nevada reversed the district court's ruling on the grounds that determination of brain death in accordance with AAN criteria could not be considered a legal determination of death, because it was not clear that the AAN criteria represented 'accepted medical standards'. They noted that great variability in the practice of brain death determination exists in US hospitals. In addition, because the Nevada statute about determination of death is based on the Uniform Determination of Death Act (UDDA), which was created in 1981, the court ruled that the Harvard Criteria (which were the accepted medical standards when the UDDA was written) should be considered the accepted medical standard for determination of brain death in Nevada ${ }^{6}$.

The Supreme Court of Nevada's finding serves as a dangerous precedent for other cases in which families might object to determination of brain death or discontinuation of organ support. Although brain death is a legal standard of death throughout the USA and, thus, organ support should be discontinued unless donation is planned $^{13,21}$, a recent survey found that half of neurologists who have declared a patient brain dead have been asked to continue organ 


\section{Table 1 | Key points in controversial brain death cases}

\begin{tabular}{|c|c|c|c|}
\hline Case & Region & Year & Key points \\
\hline $\begin{array}{l}\text { Aden } \\
\text { Hailu }^{6,38}\end{array}$ & $\begin{array}{l}\text { Nevada, } \\
\text { USA }\end{array}$ & 2015 & $\begin{array}{l}\text { - Father objected to discontinuation of organ support after } \\
\text { determination of death by neurological criteria } \\
\text { - District court ruled that organ support should be discontinued } \\
\text { because American Academy of Neurology (AAN) criteria for } \\
\text { brain death were met } \\
\text { - Supreme Court of Nevada ruled that it was unclear whether } \\
\text { AAN criteria were accepted medical standards, so organ support } \\
\text { should be continued } \\
\text { - Further legal battle ensued, but the case was dropped after Aden } \\
\text { sustained cardiac arrest (9 months after she was declared dead } \\
\text { by neurological criteria) }\end{array}$ \\
\hline $\begin{array}{l}\text { Israel } \\
\text { Stinson }\end{array}$ & $\begin{array}{l}\text { California, } \\
\text { USA }\end{array}$ & 016 & $\begin{array}{l}\text { - Mother objected to discontinuation of organ support after } \\
\text { determination of death by neurological criteria, citing that her } \\
\text { Christian faith led her to believe that Israel could be healed } \\
\text { - Legal battle ensued and organ support was continued for } \\
1 \text { month } \\
\text { - Mother found an accepting facility in Guatemala and transferred } \\
\text { Israel there } \\
\text { - After } 3 \text { months in Guatemala, Israel was transferred back to a } \\
\text { hospital in the USA } \\
\text { - Because Israel had been declared dead by neurological } \\
\text { criteria, the hospital was given permission by the district court } \\
\text { to discontinue organ support shortly after he was admitted } \\
\text { (4 months after he was declared dead by neurological criteria) }\end{array}$ \\
\hline $\begin{array}{l}\text { Jahi } \\
\text { McMath }{ }^{9,40}\end{array}$ & $\begin{array}{l}\text { California, } \\
\text { USA }\end{array}$ & 2013 & $\begin{array}{l}\text { - Mother objected to discontinuation of organ support after } \\
\text { determination of death by neurological criteria } \\
\text { - Legal battle ensued and organ support was continued for } \\
1 \text { month } \\
\text { - Mother found an accepting facility in New Jersey and transferred } \\
\text { Jahi there } \\
\text { - As of April } 2017 \text {, organ support had been continued for } \\
39 \text { months since determination of death by neurological criteria, } \\
\text { and cardiac arrest had not occurred } \\
\text { - Multiple lawsuits related to this case are ongoing }\end{array}$ \\
\hline AChild ${ }^{10}$ & UK & 2015 & $\begin{array}{l}\text { - Parents objected to discontinuation of organ support after } \\
\text { determination of death by neurological criteria, citing their } \\
\text { Muslim beliefs } \\
\text { - The coroner brought the case to the High Court of England } \\
\text { and Wales when the body was not delivered to him after } \\
\text { determination of death } \\
\text { - The High Court ruled that organ support should be discontinued } \\
\text { (2 days after determination of death by neurological criteria) }\end{array}$ \\
\hline
\end{tabular}

support after brain death determination at some point during their careers ${ }^{22}$. Families request continuation of organ support for a variety of reasons, including belief that a brain-dead patient could regain neurological function; lack of acceptance that a person could be dead if the heart is still beating; desire to continue receiving social security benefits; and religious beliefs ${ }^{22}$.

Management of these requests is challenging. On the one hand, there is the desire to avoid conflict, be compassionate and respectful to families, and uphold the principles of autonomy, individualism, privacy and religious freedom ${ }^{23,24}$. On the other hand, hospitals are facilities for the living, treatment after death can be considered abuse, and allowing a negotiated standard for management after brain death but not after cardiopulmonary death is ethically precarious ${ }^{22,23}$. Discontinuation of organ support after determination of brain death does not require family consent; however, in a survey of neurologists, none of the respondents endorsed overruling a family's objection ${ }^{22}$. Some families who initially object to discontinuation of organ support ultimately come to terms with a patient's death ${ }^{22}$, whereas others - as in the Hailu case - elect to use the judicial system to prevent hospitals from discontinuing support. As the Supreme Court of Nevada's finding casts doubt on the authority of the AAN criteria ${ }^{6}$, the Hailu case can be referenced by any family arguing to continue organ support after determination of brain death.

The Hailu case was referenced in a trial about Israel Stinson, another brain-dead patient whose case was brought to court in California in 2016. Israel, a 2-year-old boy, had a $40 \mathrm{~min}$ respiratory arrest after an asthma attack. He was subsequently declared brain dead, but his mother objected to discontinuation of organ support, citing that her Christian faith led her to "believe in the healing power of God." She obtained a court order to continue organ support and sought to establish home care or transfer to another facility. After an extensive search, she was able to find an accepting hospital in Guatemala. After treatment in Guatemala for a few months, she arranged for Israel to be accepted by another hospital in California. When he arrived, however, the hospital planned to discontinue organ support because he was brain dead. The family sought judicial relief, but the court ruled in favour of the hospital and allowed support to be discontinued ${ }^{7,8}$.

Although the clinicians continued organ support pursuant to the court order before Israel was transferred to Guatemala, they did not allow his mother to persuade them to continue nutrition (other than intravenous dextrose), or place a tracheostomy or feeding tube ${ }^{7,8}$. Survey results have shown that management after religious objection to brain death varies: $50 \%$ of respondents would continue intravenous fluids, $40 \%$ would continue nutrition, 35\% would continue vasopressors, and $25 \%$ would continue antibiotics. Although over $80 \%$ of respondents would not start any new therapies in this setting, $4 \%$ would be willing to place a tracheostomy ${ }^{22}$.

Most hospital protocols do not address family objections to determination of death by neurological criteria ${ }^{23}$. As a result, physicians, nurses, administrators and ethics committees are left without guidance to determine whether to continue organ support and await cardiac arrest while hoping the family comes to terms with the determination of brain death, or to discontinue organ support against the family's wishes ${ }^{25}$. In a survey, neurologists were asked what action they would take if a family voiced religious objection to discontinuation of organ support after determination of brain death ${ }^{22}$. Each respondent was allowed to cite more than one reason to continue organ support in this situation, and the reasons given included fear of litigation ( $48 \%$ of respondents), proclivity to avoid upsetting the family (40\%), desire to avert media coverage (29\%) and, for a small percentage of respondents, personal religious or ethical beliefs, or fear of job termination. 
To avoid choosing between allocating resources (intensive care unit bed, ventilator, medications and clinician time) to a dead patient or discontinuing organ support against a family's wishes, a small percentage $(0.6 \%)$ of hospital protocols recommend transfer of a brain-dead patient to another clinician or facility if the family objects to discontinuation of organ support $^{23}$. However, transfer of brain-dead patients to other institutions is extremely rare, and is not a practice that is condoned or encouraged.

Israel Stinson's family was inspired to seek an accepting facility by the case of Jahi McMath ${ }^{7,8}$. In 2013, Jahi had a cardiac arrest after a tonsillectomy and was subsequently pronounced brain dead. Her mother objected to discontinuation of organ support and, after a lengthy legal battle, Jahi was transferred from California to New Jersey where organ support was continued?.

Jahi was able to be transferred to New Jersey because laws about management of brain-dead patients in the setting of moral or religious objection to determination of death by neurological criteria vary across the USA ${ }^{26}$. In California and New York, state laws and guidelines indicate that reasonable accommodation must be provided to families who voice religious or moral objection to determination of death by neurological criteria ${ }^{27,28}$. Institutions must individually decide how to interpret the phrase 'reasonable accommodation'. In Illinois, clinicians are told to take a patient's religious beliefs into account when determining time of death ${ }^{29}$. Again, it is left up to each hospital to determine the meaning of the phrase 'take into account'. In New Jersey, if determination of brain death would violate a patient's religious beliefs, then death is declared solely on the basis of cardiopulmonary criteria ${ }^{30}$. No other states have rules or guidelines about this situation; thus, New Jersey is the only state that offers concrete regulations on how to manage scenarios in which families voice religious objection to determination of brain death ${ }^{26}$.

Although religious objections to determination of death by neurological criteria are acknowledged in some places in the USA ${ }^{27-30}$, management of this situation varies internationally ${ }^{10,31}$. In 2015, after 'A Child' (name withheld by the court) was determined dead by neurological criteria in the UK, her Muslim parents voiced religious objection to discontinuation of organ support. The High Court of England and Wales did not view this case as a religious dispute and dismissed the objection as that of parents unable to accept the death of their child. Consequently, discontinuation of organ support was permitted ${ }^{10,31}$.

\section{Controversies in brain death}

The cases of Hailu, Stinson, McMath, and A Child are just a sample of lawsuits involving objections to brain death determination or discontinuation of organ support, which illustrate that controversies about brain death persist ${ }^{6-10}$. Despite the fact that the majority of the medical, legal and ethical communities support the notion that brain death is equivalent to death ${ }^{1-3,22}$, some people disagree. Such disputes can have a negative impact on families, health-care professionals and society, and can result in lengthy lawsuits , $8,9,23,25$.

Protocol variability. At the procedural level, protocols for brain death determination need to satisfy minimal criteria and be consistent between hospitals, at least within countries, if not worldwide. An international survey ${ }^{16}$ found that the presence of institutional protocols for determination of death by neurological criteria varied markedly according to national wealth ( $97 \%$ of high-income countries versus $22 \%$ of low-income countries, $P<0.001)$. The majority (56\%) of respondents reported having distinct criteria for determination of death by neurological criteria in paediatric patients ${ }^{16}$.

The AAP criteria for determination of brain death in paediatric patients are comparable but not identical to the AAN brain death criteria for adults. To ensure that neurological dysfunction is not secondary to hypothermia, which can suppress brainstem function, body temperature must be above $36^{\circ} \mathrm{C}$ in adult patients, but only needs to be above $35^{\circ} \mathrm{C}$ in paediatric patients. In the apnoea test, the partial pressure of carbon dioxide $\left(\mathrm{PaCO}_{2}\right)$ must rise to $\geq 60 \mathrm{mmHg}$ or to $20 \mathrm{mmHg}$ above baseline in adults, but in paediatric patients, it must rise to both $\geq 60 \mathrm{mmHg}$ and $20 \mathrm{mmHg}$ above baseline. The key difference between determination of brain death in adults and paediatric patients is that brain death determination in adults can rely on only one examination, whereas determination in paediatric patients mandates two examinations by different physicians. Ancillary tests may be used to shorten the 'observation period', which for adult patients is the interval before an examination is conducted (for example, when confounders are present and cannot be corrected for), and for paediatric patients is the interval between examinations ${ }^{13,14,18,19}$. Ideally, the adult and paediatric communities should work together to create a single set of guidelines for determination of brain death in all individuals $>30$ days of age.

Of note, a review of 1,229 adult and 82 paediatric patients (aged $1-18$ years) pronounced brain dead using two examinations found that none of the patients regained neurological function between the two examinations, and the use of a second examination was associated with inflated intensive care unit costs and loss of viable organs for donation ${ }^{32}$. Nevertheless, the paediatric brain death guideline committee felt that two examinations should be required to ensure the integrity of the determination ${ }^{19}$.

The goal of the AAN practice parameter revision in 2010 was to make brain death determination simple and straightforward. However, not all institutions updated their brain death protocols to mirror the AAN criteria ${ }^{17}$. Current protocols do not uniformly describe the need to rule out confounding conditions that can cause false-positive brain death determinations. This situation can lead to stories of 'recovery from brain death' (see below) that erode public trust in medical practice and destroy the notion of the irreversibility of brain death, or to inappropriate termination of a living patient's life support. Qualifications for examiners vary, and examinations might, therefore, be conducted by inexperienced individuals or those without specific neurological expertise ${ }^{17}$. When a group of neurologists and neurosurgeons were given a test about the intricacies of brain death determination, they correctly answered only $54 \%$ of the questions ${ }^{33}$, emphasizing the importance of education and re-education. When making the distinction between life and death, there is no room for error. At present, no certification process is available for clinicians who determine brain death, although there are active movements within medical societies to develop such a process.

\section{AAN criteria as accepted medical}

standards. The Hailu case cast doubt on the authority of the AAN criteria ${ }^{6}$. State laws about determination of death are based on the UDDA ${ }^{5,21}$, which states that "an individual who has sustained either irreversible cessation of circulatory and respiratory functions, or irreversible cessation of all functions of the entire brain, including the brainstem, is dead. A determination of death must be made 
in accordance with accepted medical standards." When the updated AAN brain death guidelines were published in 2010, they were endorsed by the Neurocritical Care Society, the Child Neurology Society, the Radiological Society of North America, and the American College of Radiology ${ }^{14}$, indicating widespread acceptance. The authors of the UDDA deliberately chose the term 'accepted' because it did not require a procedure to be universally adopted, but simply "accepted by a substantial and reputable body of medical men and women as safe and efficacious for the purpose for which it is being employed." (REF. 5) Nonetheless, because the Hailu case questioned whether the AAN criteria are 'accepted medical standards', it is critical that medical societies publicly and emphatically endorse the AAN guidelines. Governmental approval of - and requirement of adherence to - the AAN criteria could help to prevent future disputes.

Management of objections to brain death. The fact that the Hailu, Stinson, McMath and A Child cases resulted in lawsuits and garnered substantial publicity highlights the lack of guidance for clinicians about how to handle objections to discontinuation of organ support after determination of brain death $^{6-10}$. Few institutional protocols address requests to continue organ support after determination of brain death, and those that do address these requests offer varying instructions ${ }^{23}$. Legal guidelines about the management of this situation are scarce and often provide vague recommendations ${ }^{22,27-31}$. Medical societies such as the AAN, the Neurocritical Care Society and the Society of Critical Care Medicine do not provide any instructions about scenarios in which physicians can or should continue organ support, the timeframe for provision of organ support, or maintenance or initiation of fluids, nutrition, vasopressors or antibiotics ${ }^{22}$. Clearly, more guidance is necessary for these situations, which seem to be increasingly common.

'Recovery' from brain death. Reports of recovery from brain death damage the credibility of brain death determinations. When reporting about brain death, the media often provide misinformation to the general public, suggesting that recovery from brain death is possible ${ }^{34}$. The Quality Standards Subcommittee of the AAN conducted a literature search of MEDLINE and Embase from 1996 to 2009 before publishing the 2010 brain death criteria, and they confirmed that no recovery of neurological function had been observed after determination of brain death on the basis of the 1995 AAN criteria. Nonetheless, they noted reports of brain death mimics, including Guillain-Barré syndrome, organosphosphate poisoning, high cervical spine injury, lidocaine toxicity, baclofen overdose, and delayed neuromuscular blockade clearance, from which recovery could inappropriately be deemed 'recovery from brain death' (REF. 14). In our view, all reports of recovery from brain death are based on errors in brain death determination and under-appreciation of the careful stepwise process ${ }^{35}$.

10 months after Jahi McMath was transferred to New Jersey, her family's lawyer petitioned to have her declared alive again. Reportedly, the International Brain Research Foundation performed an EEG that showed electrical activity, an MRI scan that showed an intact brain structure, and a magnetic resonance angiogram (MRA) that showed blood flow to the brain As a result of the reports of these ancillary tests, Dr Alan Shewmon, a neurologist at the University of California, Los Angeles, concluded that Jahi did not meet the criteria for brain death ${ }^{36}$. However, ancillary tests can be flawed and can lead to confusion about a patient's status ${ }^{35}$. For example, patients who have an isoelectric EEG can have persistent cranial nerve functioning in the setting of hydrocephalus, intoxication, hypothermia or metabolic encephalopathy, so the clinical examination should always trump an ancillary test ${ }^{12,35}$. Similarly, EEG activity can reflect environmental artefact, making it difficult to determine whether the electrical activity originates from the brain ${ }^{35}$. MRI and MRA are not recommended tests for brain death ${ }^{14,20}$.

Dr Shewmon did not conduct a physical examination of Jahi McMath and instead relied on the results of ancillary tests (including unapproved tests) to determine her status. By contrast, Dr Paul Fisher, a neurologist at Stanford, performed a clinical evaluation - as stipulated by both the adult and paediatric criteria for brain death determination $^{14,20}$ - and reported that there was no evidence that Jahi was alive ${ }^{36}$. Therefore, Dr Fisher's findings negated Dr Shewmon's suggestion that Jahi had recovered from brain death ${ }^{36}$.

\section{Conclusions}

Despite the fact that death by neurological criteria is legally and conceptually valid ${ }^{1-5}$, controversies promulgated by those who believe that it is a legal fiction continue to emerge ${ }^{4}$. Opponents of brain death, who are clearly in the minority, argue that because the heart can continue beating for a protracted period after brain death in patients who are continued on organ support, brain death should not be considered death, and that the time of death should be a matter of philosophical, religious, legal and policy choice, not a simple biological event ${ }^{37}$. However, both the adult and paediatric brain death criteria ensure complete loss of function of the brain, just as the criteria for cardiopulmonary death ensure complete loss of function of the heart and lungs ${ }^{14,20}$. Consequently, brain death is accepted as death throughout the USA, as per the UDDA ${ }^{5,21}$.

It is imperative that we work to eliminate the controversies associated with brain death; death should not be subjective or variable. A patient who is dead in one location should be dead everywhere, and patients declared dead according to neurological criteria should be treated the same as patients declared dead according to cardiopulmonary criteria. To this end, medical societies and governmental regulatory bodies must endorse the AAN criteria in order to authenticate these guidelines as 'accepted medical standards' and prevent further protocol variability. In addition, variability in the laws about management of religious or moral objections to brain death determination damages the credibility of the determination, and these objections should be handled in a uniform manner ${ }^{22}$.

Ariane Lewis is at the NYU Langone Medical Center, Departments of Neurology and Neurosurgery, Division of Neurocritical Care, 530 First Avenue HCC-5A, New York, New York 10016, USA.

David Greer is at the Division of Neurocritical Care, Department of Neurology, Yale University School of Medicine, LLCI 912, 15 York Street, New Haven, Connecticut 06520, USA.

Correspondence to D.G. david.greer@yale.edu doi:10.1038/nrneurol.2017.72 Published online 26 May 2017

1. Sprung, C. L. et al. Seeking worldwide professional consensus on the principles of end-of-life care for the critically ill. The Consensus for Worldwide End-of-Life Practice for Patients in Intensive Care Units (WELPICUS) study. Am. J. Respir. Crit. Care Med. 190, 855-866 (2014).

2. Shemie, S. D. et al. International guideline development for the determination of death. Intensive Care Med. 40, 788-797 (2014).

3. Burkle, C. M., Sharp, R. R. \& Wijdicks, E. F. Why brain death is considered death and why there should be no confusion. Neurology 83, 1464-1469 (2014).

4. Bernat, J. L. Controversies in defining and determining death in critical care. Nat. Rev. Neurol. 9, 164-173 (2013). 
5. President's Commission for the Study of Ethical Problems in Medicine and Biomedical and Behavioral Research. Defining Death: a Report on the Medical, Legal and Ethical Issues in the Determination of Death (United States Government Printing Office, 1981).

6. In Re: Guardianship of Hailu 361 P.3d 5 (2015).

7. Jonee Fonseca v. Kaiser Permanente Medical Center 2:16-cv-00889-KJM-EFB (2016).

8. Israel Stinson v. Children's Hospital Los Angeles BS164387 (2016).

9. McMath vs. California No. 3, 15-06042 N.D. Cal. (2015).

10. Re: A (A Child) EWHC 443 (Fam) (2015).

11. [No authors listed.] A definition of irreversible coma. Report of the Ad Hoc Committee of the Harvard Medical School to Examine the Definition of Brain Death. JAMA 205, 337-340 (1968).

12. Powner, D. J., Snyder, J. V. \& Grenvik, A. Brain death certification. A review. Crit. Care Med. 5, 230-233 (1977).

13. Wijdicks, E. F. Determining brain death in adults. Neurology 45, 1003-1011 (1995).

14. Wijdicks, E. F., Varelas, P. N., Gronseth, G. S. \& Greer, D. M. Evidence-based guideline update: determining brain death in adults: report of the Quality Standards Subcommittee of the American Academy of Neurology. Neurology 74, 1911-1918 (2010).

15. Ding, Z.-Y., Zhang, Q., Wu, J.-W., Yang, Z.-H. \& Zhao, X.-O. A. Comparison of brain death criteria between China and the United States. Chin. Med. J. (Engl.). 128, 2896-2901 (2015).

16. Wahlster, S. et al. Brain death declaration: practices and perceptions worldwide. Neurology 84 1870-1879 (2015).

17. Greer, D. M. et al. Variability of brain death policies in the United States. JAMA Neurol. 73, 213-218 (2016).

18. [No authors listed.] Report of special Task Force. Guidelines for the determination of brain death in children. American Academy of Pediatrics Task Force on Brain Death in Children. Pediatrics 80, 298-300 (1987).

19. Mathur, M. \& Ashwal, S. Pediatric brain death determination. Semin Neurol 35, 116-124 (2015).

20. Nakagawa, T. A., Ashwal, S., Mathur, M., Mysore, M. $\&$ Committee for Determination of Brain Death in
Infants Children. Guidelines for the determination of brain death in infants and children: an update of the 1987 task force recommendations - executive summary. Ann. Neurol. 71, 573-585 (2012).

21. Burkle, C. M., Schipper, A. M. \& Wijdicks, E. F. Brain death and the courts. Neurology 76, 837-841 (2011).

22. Lewis, A., Adams, N., Varelas, P., Greer, D. \& Caplan, A. Organ support after death by neurologic criteria: results of a survey of US neurologists. Neurology 87, 827-834 (2016).

23. Lewis, A., Varelas, P. \& Greer, D. Prolonging support after brain death: when families ask for more. Neurocrit. Care 24, 481-487 (2016).

24. Burt, R. A. The medical futility debate: patient choice, physician obligation, and end-of-life care. J. Palliat. Med. 5, 249-254 (2002).

25. Flamm, A. L., Smith, M. L. \& Mayer, P. A. Family members' requests to extend physiologic support after declaration of brain death: a case series analysis and proposed guidelines for clinical management. J. Clin. Ethics 25, 222-237 (2014).

26. Lewis, A., Varelas, P. \& Greer, D. M. Controversies after brain death: when families ask for more. Chest 149, 607-608 (2015)

27. [No authors listed.] California health and safety code section 1254.4. FindLaw http://codes.findlaw.com/ca/ health-and-safety-code/hsc-sect-1 254-4.html (2008).

28. New York State Department of Health \& New York State Task Force on Life and the Law. Guidelines for determining brain death. New York State Department of Health http://www.health.ny.gov/professionals/ hospital administrator/letters/2011/brain death guidelines.htm (2011).

29. [No authors listed.] Illinois Compiled Statutes 210 ILCS 85 Hospital Licensing Act. Section 6.24. Onecle http://law.onecle.com/illinois/210ilcs85/6.24.html (2008)

30. New Jersey Ad Hoc Committee on Declaration of Death by Neurologic Criteria. Guidelines for determining death based on neurological criteria. NJ Sharing Network http://www.njsharingnetwork.org/ file/Brain-Death-Guidelines-July-27-2014sq-2.pdf (2014).

31. Choong, K. A. \& Rady, M. Y. Re A (A Child) and the United Kingdom Code of Practice for the Diagnosis and Confirmation of Death: should a secular construct of death override religious values in a pluralistic society? HEC Forum http://dx.doi.org/10.1007/ s10730-016-9307-y (2016).

32. Lustbader, D. et al. Second brain death examination may negatively affect organ donation. Neurology 76 . 119-124 (2011).

33. MacDougall, B. J., Robinson, J. D., Kappus, L., Sudikoff, S. N. \& Greer, D. M. Simulation-based training in brain death determination. Neurocrit. Care 21, 383-391 (2014)

34. Lewis, A., Lord, A. S., Czeisler, B. M. \& Caplan, A. Public education and misinformation on brain death in mainstream media. Clin. Transplant. 30, 1082-1089 (2016).

35. Wijdicks, E. F. The case against confirmatory tests for determining brain death in adults. Neurology 75 77-83 (2010).

36. Lewis, A. The history of brain death and how the Jahi McMath case will impact future brain dead patients. Med. Law 34, 497-508 (2015).

37. Karakatsanis, K. G. 'Brain death': should it be reconsidered? Spinal Cord 46, 396-401 (2008)

38. NY Daily News. 20-year-old woman involved in months-long court battle over treatment at Reno hospital dies on life support. NY Daily News http://www.nydailynews.com/news/national/womaninvolved-suit-treatment-reno-hospital-diesarticle-1.2486229 (2016)

39. Buck, C. Brain-dead toddler taken off life support in Los Angeles. The Sacramento Bee http://www.sacbee. com/news/local/article97861097.html (2016).

40. Proctor, K. Wrangling continues on brain dead teen Courthouse News Service http://www. courthousenews. com/wrangling-continues-on-brain-dead-teen/ (2016).

Author contributions

Both authors researched the data for the article, provided substantial contributions to the discussion of the content, wrote the article, and reviewed and/or edited the manuscript before submission.

Competing interests statement

The authors declare no competing interests.

Publisher's note

Springer Nature remains neutral with regard to jurisdictional claims in published maps and institutional affiliations. 